\title{
A RELAÇÃO DE GRUPOS SOCIAIS COM O PARQUE NACIONAL DA SERRA DA BODOQUENA
}

\section{THE RELATIONSHIP OF SOCIAL GROUPS WITHIN THE SERRA DA BODOQUENA NATIONAL PARK}

\section{LA RELACIÓN DE LOS GRUPOS SOCIALES CON EL PARQUE NACIONAL SIERRA DA BODOQUENA}

\author{
Ângelo Franco do N. Ribeiro \\ Mestre em Geografia pela Universidade Federal da Grande Dourados e \\ Técnico de Laboratório de Geoprocessamento na mesma instituição. \\ Rodovia Dourados - Itahum, Km 12 \\ CEP: 79.804-970, Dourados - MS \\ angeloribeiro@ufgd.edu.br \\ Edvaldo Cesar Moretti \\ Professor dos cursos de Graduação e Pós-Graduação em Geografia da \\ Universidade Federal da Grande Dourados. \\ edvaldomoretti@ufgd.edu.br
}

\begin{abstract}
Resumo
A área de estudo é o Parque Nacional da Serra da Bodoquena, criado no ano de 2000, com uma área de 76.481 hectares, localizado no Planalto da Bodoquena, faixa de fronteira Brasil/Paraguai, e idealizado por meio de estudos técnicos realizados pelo IBAMA e por Universidades da região, que fundamentaram a decisão de proteger esta região, além disso também realizaram-se audiências públicas para ouvir a comunidade local. Durante a pesquisa, constatou-se dois pontos marcantes: de um lado as comunidades da área sobretudo o Assentamento Canaã do início da década de 1980, implantado em uma "reserva florestal", pois na época a área era coberta por mata; de outro lado, o PNSB, criado no início dos anos 2000 carregado de contradição e disputas. Este impasse perdura até o momento, contado, aproximadamente, uma década de criação, e busca-se a separação dos assentados de seus lotes, ou seja, a fragmentação do homem e natureza, e acredita-se que dessa forma o Parque estará "protegido".
\end{abstract}

Palavras-Chave: Produção do Espaço; Unidade de Conservação; Preservação; Conflito.

\begin{abstract}
The area to be studied is the Serra da Bodoquena National Park, created in the year of 2000, with an area of 76.481 hectares, located in the Planalto da Bodoquena, within the borderline Brazil/Paraguay, and it was idealized by means of technical studies performed by the IBAMA and by the universities of the region that have founded the decision to protect this region. Besides, there have also been public audiences in order to listen to the local community. During the research, two interesting points have been highlighted: on one hand, the communities in the area with special attention to the Canaã Settlement in the beginning of the eighties, which was implanted in a Forest
\end{abstract}


reserve since the area was covered by grasslands in that time; on the other hand, the PNSB, created in the beginning of the year 2000 followed by contradiction and disputes. This impasse lasts until now, i.e., approximately a decade of creation and it is intended to find the separation of the settlement people in their plot. In their words, this is the fragmentation mankind-nature, and it is believed that the Park will be safe by doing this.

Key words: Production of the Space; Unity of Conservation; Preservation; Conflict.

\section{Resumen}

El área de estudio es el Parque Nacional Sierra da Bodoquena, creado en 2000, con una superficie de 76.481 hectáreas, ubicado en el altiplano de Bodoquena, franja fronteriza entre Brasil y Paraguay, e idealizado a través de estudios técnicos realizados por el IBAMA y las universidades de la región, que justificaron la decisión de proteger esta región. Además también se realizaron audiencias públicas para escuchar a la comunidad local. Durante la investigación, encontramos dos puntos notables: por un lado, las comunidades del área, especialmente el asentamiento rural de Canaã en el comienzo de la década de 1980, implantado en una "reserva forestal", porque en ese momento el área estaba cubierta por bosques, por otro lado hay el PNSB, creado a principios de 2000 lleno de contradicciones y conflictos. Este problema se prolongó hasta el momento y cuenta aproximadamente una década de la creación, y busca la separación de los pobladores de la tierra, es decir, la fragmentación del hombre y la naturaleza, y se cree que así el parque será "protegido".

Palabras clave: Producción del Espacio, la Unidad de Conservación, Protección, Conflicto.

\section{Introdução}

Este trabalho faz parte da dissertação defendida no Programa de PósGraduação em Geografia da Universidade Federal da Grande Dourados. Na íntegra o trabalho teve como ponto central o processo de implantação de uma Unidade de Conservação e sua relação com as populações residentes na área. Com este objetivo, delimitou-se para estudo o Parque Nacional da Serra da Bodoquena-PNSB e o Assentamento Canaã. A partir da temática e das discussões realizadas no grupo de pesquisas Território e Ambiente ${ }^{1}$, onde as discussões são relativas às transformações territoriais provocadas pelo turismo e pela implantação de unidades de conservação e seus conflitos.

Neste estudo procura-se analisar a implantação do PNSB e as consequencias socioambientais para as comunidades residentes na área da Unidade de Conservação-

\footnotetext{
${ }^{1}$ Vinculado ao Laboratório de Pesquisas Territoriais - LAPET da Universidade Federal da Grande Dourados - UFGD.
} 
UC e entorno denominado Zona de Amortecimento ${ }^{2}$ que compreende 10.000 metros de raio, na perspectiva da análise da transformação do público em privado, considerando o uso do solo como elemento de análise geográfica. A partir deste foram delimitados vários itens para compreensão do processo de criação e transformação do espaço na área do entorno e, posteriormente, do Parque.

Pensando a relação entre a evolução das ferramentas de observação e o estudo do espaço, recorreu-se a Moreira, R. (2002), que trata da ideia moderna de espaço:

A idéia moderna de espaço evolui desde o berço na arte medieval da baixa Idade Média até a física moderna de Newton e a filosofia iluminista de Kant. Uma trajetória contada através das formas no tempo das cartas e mapas. (p. $10)$.

Entende-se que o desenvolvimento de tecnologias computacionais, do sensoriamento remoto e consequentemente da geotecnologia tem ampliado o campo de pesquisas no âmbito da ciência geográfica, sobretudo, nas questões relacionadas ao meio ambiente e o estudo das transformações do espaço geográfico.

Este fato tem auxiliado a tomada de decisões em projetos de criação de UC e assentamentos o que demonstra que a área em questão foi criada sem os devidos cuidados técnicos, sobretudo pelo fato de englobar comunidades de assentados na área do Parque e entorno.

Desta forma analisa-se a implantação do PNSB para as comunidades inseridas no processo de criação e gerenciamento da unidade e a caracterização dos municípios inseridos na área em questão.

\section{O Parque como território da conservação e distanciamento da terra para os assentados}

O PNSB foi criado no ano de $2000^{3}$ através de Decreto ${ }^{4}$, com uma área de $76.481 \mathrm{ha}^{5}$ localizado no Planalto da Bodoquena, na faixa de fronteira Brasil/Paraguai, e

\footnotetext{
${ }^{2}$ LEI No 9.985, DE 18 DE JULHO DE 2000.

${ }^{3}$ Em 1986, o Macrozoneamento Geoambiental do Mato Grosso do Sul sugeriu a proteção da área na Serra da Bodoquena. (ICMBio)

4 DECRETO S/N DE 21 SETEMBRO DE 2000.

51 Hectare (ha) corresponde a $10.000 \mathrm{~m}^{2}$.
} 
foi idealizado por meio de estudos técnicos realizados pelo IBAMA e Universidades da região. Estes fundamentaram a decisão de proteger esta região e contaram também com a realização de audiências públicas para ouvir a comunidade local. Alguns segmentos da sociedade queriam a criação de $\mathrm{APA}^{6}$.

O PNSB faz parte das Unidades de Conservação de Proteção Integral, que de acordo com Batarce (2004):

(...) não é permitido promover alterações no meio ambiente nem interferência humana direta. Nessas Unidades são executadas medidas de recuperação de seus sistemas alterados e ações de manejo necessárias para recuperar e preservar o equilíbrio natural, a diversidade biológica e os processos naturais, segundo o que estiver estabelecido em seu plano de manejo. (p. 80).

A criação de Parques é conflitante numa economia de mercado. Essa atitude impõe limites ao poder da ação e destruição das riquezas naturais pelos homens e indústrias. Por outro lado, o rigor do modelo de criação de Parques e das práticas de implantação tem gerado inúmeros conflitos para as populações locais e, consequentemente, obstáculos para os objetivos propostos, ou seja, a preservação e/ou conservação da área. O modelo exclui a permanência de moradores em seu interior e, muitas vezes, essas áreas estão habitadas. O PNSB possui parte do Assentamento Canaã dentro de seus limites e mais 3 na Zona de Amortecimento.

6 Durante este processo, a questão evoluiu com a formulação de duas propostas muito claras: a proposta de criação do Parque Nacional da Serra da Bodoquena e a proposta da FAMASUL de, ao invés de um parque, ser criada uma APA - Área de Proteção Ambiental. (BOGGIANI, 2007). 


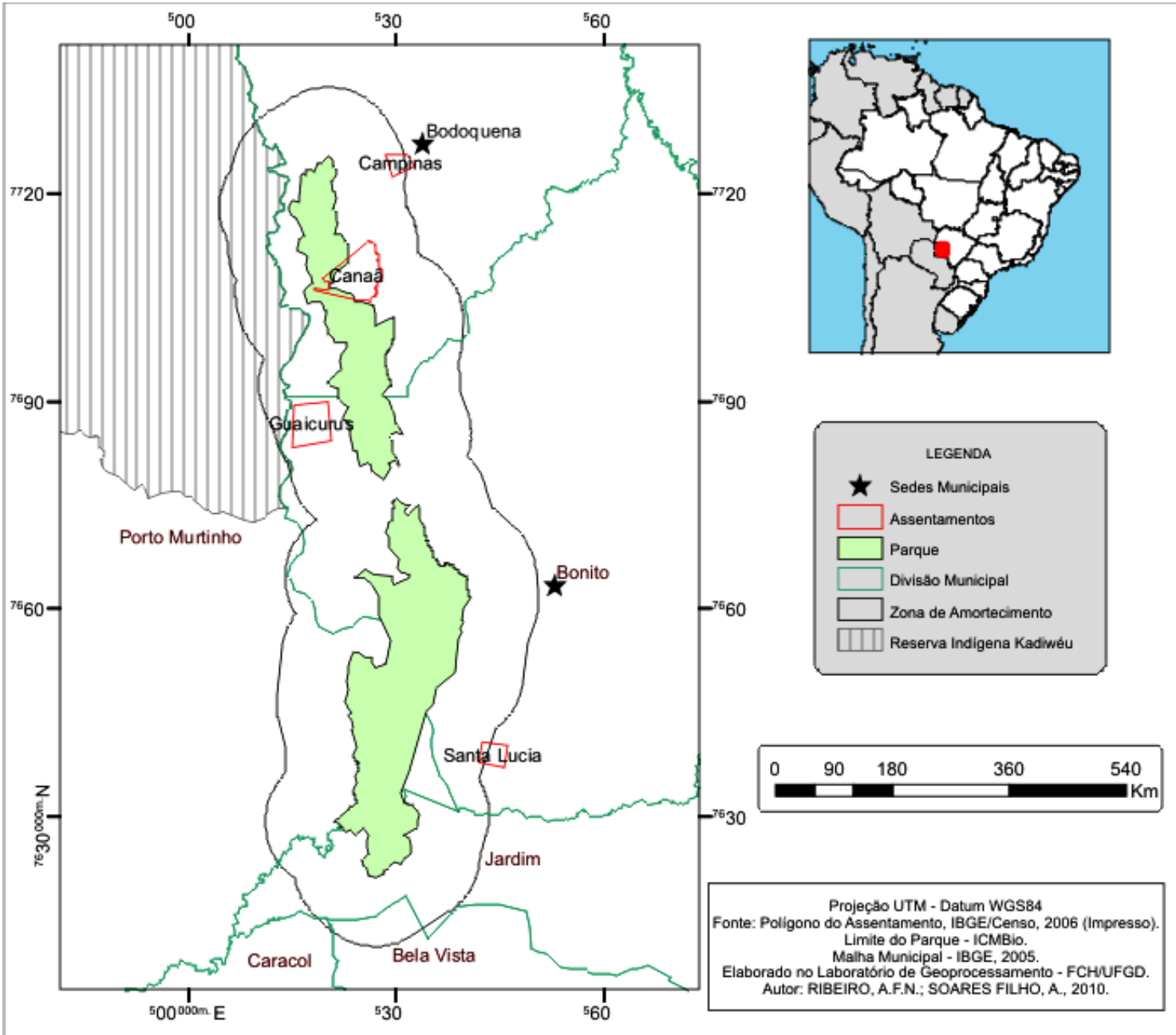

O PNSB abrange os municípios de Bodoquena, Jardim, Porto Murtinho e Bonito. Dentre estes, o último é o que abrange a maior área da Unidade, como mostra mapa, a tabela e gráfico a seguir.

Tabela 1 - Situação dos municípios da Unidade de Conservação.

\begin{tabular}{l|c|c|c|c|c}
\hline Município & $\begin{array}{c}\text { Área em HA } \\
\text { da UC }\end{array}$ & $\begin{array}{c}\text { \% da UC em cada } \\
\text { Município }\end{array}$ & $\begin{array}{c}\text { Área do } \\
\text { Município (ha) }\end{array}$ & $\begin{array}{c}\text { Pop. Do } \\
\text { Município } \\
\text { (2009) }\end{array}$ & $\begin{array}{c}\text { \% do município } \\
\text { na UC }\end{array}$ \\
\hline Bodoquena & 20673 & 27 & 250.700 & 8.397 & 8,2 \\
\hline Bonito & 25729 & 34 & 493.400 & 17.856 & 5,2 \\
\hline Jardim & 5224 & 7 & 220.200 & 24.174 & 2,4 \\
\hline $\begin{array}{l}\text { Porto } \\
\text { Murtinho }\end{array}$ & 24855 & 32 & 1.773 .500 & 15.527 & 1,4 \\
\hline
\end{tabular}

Fonte: IBGE, 2000.

Org.: RIBEIRO, A.F.N., 2010. 


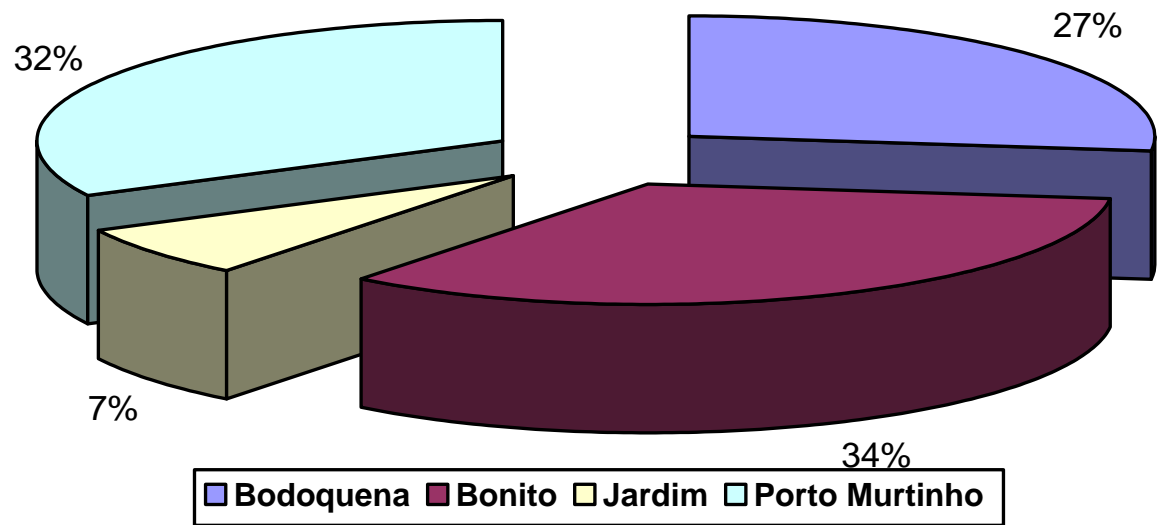

Figura 1 - Área da Unidade de Conservação em cada Município em porcentagem.

Levando em consideração a Resolução do Conama $^{7}$, em um raio de $10 \mathrm{Km}$ da UC o uso do solo deve obedecer à legislação específica e neste caso os municípios que fazem parte da zona de amortecimento do Parque são Bela Vista, Bodoquena, Bonito, Caracol, Jardim e Porto Murtinho. O município com maior área dentro da faixa de transição do Parque é Bonito com mais de 130.000 ha, como segue a tabela e o gráfico.

Tabela 2 - Situação dos municípios da Zona de Amortecimento.

\begin{tabular}{l|c|c|c|c}
\hline Município & $\begin{array}{c}\text { Área em HA da } \\
\text { ZA }\end{array}$ & $\begin{array}{c}\text { \% da ZA em cada } \\
\text { Município }\end{array}$ & $\begin{array}{c}\text { Área do Município } \\
\text { (ha) }\end{array}$ & $\begin{array}{c}\text { \% do município na } \\
\text { ZA }\end{array}$ \\
\hline Bela Vista & 5381 & 1,5 & 489.600 & 1,1 \\
\hline Bodoquena & 88330 & 24,8 & 250.700 & 35,2 \\
\hline Bonito & 130567 & 36,7 & 493.400 & 26,5 \\
\hline Caracol & 239 & 0,1 & 293.900 & 0,1 \\
\hline Jardim & 36748 & 10,3 & 220.200 & 16,7 \\
\hline $\begin{array}{l}\text { Porto } \\
\text { Murtinho }\end{array}$ & 94739 & 26,6 & 1.773 .500 & 5,3 \\
\hline
\end{tabular}

Fonte: IBGE, 2000.

Org.: RIBEIRO, A.F.N., 2010.

7 Brasil, (1990). 


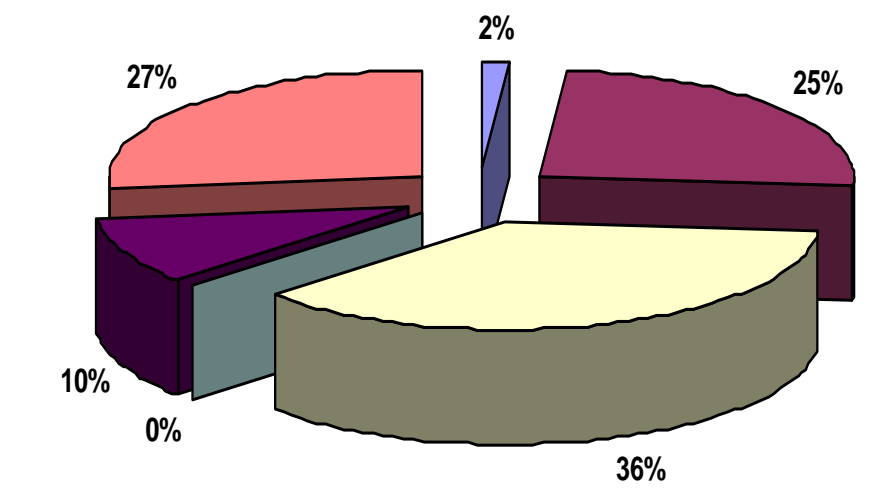

$\square$ Bela Vista $\square$ Bodoquena $\square$ Bonito $\square$ Caracol $\square$ Jardim $\square$ Porto Murtinho

Figura 2 - Área da zona de amortecimento em cada Município em porcentagem.

A área onde o Parque foi instalado é muito rica em atrativos turísticos, mas a única cidade onde esta atividade tem expressividade é Bonito, pois possui uma infraestrutura consolidada para desenvolvimento desta prática.

A região onde atualmente estão os municípios de Jardim, Bodoquena, Bonito e Porto Murtinho foi alvo de impasse territorial, primeiramente entre Portugal e Espanha, posteriormente entre Brasil e Paraguai. Isso só se resolveu ao fim da Guerra do Paraguai (1864-1870), que marca também o início da ocupação branca no sudoeste do atual Mato Grosso do Sul. Até então, a região era habitada por indígenas, com baixa densidade populacional, com destaque para os Mbaiás e Paiaguás, da família linguística guaicurus. Guerreiros, eles foram de certa forma um contraponto à colonização enquanto esta não era prioridade até meados do século XVIII ${ }^{8}$.

Atualmente, somente duas etnias autóctones apresentam população que permite sua existência em comunidade nos arredores da unidade: Kadiwéus e Terenas, somando menos de 2.000 pessoas. Os primeiros se distribuem principalmente nas aldeias Barro Preto, Tomázia, Bodoquena (antiga Alves de Barros) e Campina, todas fora da zona de amortecimento, na Terra Indígena Kadiwéu (538.536 ha). Porém, na aldeia São João, a etnia mais numerosa é a Terena, herança de um passado em que esses povos eram cativos (vassalos) dos Kadiwéus. Ainda nessa aldeia, encontram-se alguns indivíduos de uma etnia quase extinta, os Quiniquinauas ${ }^{9}$.

8 ICMBio.

${ }^{9}$ ICMBio, Op. cit. 
Nas referências consultadas, o único povoamento Kadiwéu na Serra da Bodoquena, em sua porção oeste setentrional, se dá na aldeia de Xatelodo, já no município de Miranda, fora da delimitação da Reserva Indígena e dos limites da faixa de entorno do Parque. Nas épocas de conflito, os índios usavam a Serra como esconderijo, mas até o momento não foram levantadas referências que indiquem algum tipo de vínculo forte dos indígenas com a Serra da Bodoquena. O dado mais expressivo a esse respeito é o fato de o divisor de águas da Serra (que está fora do Parque) servir como limite à parte das terras dos índios ${ }^{10}$.

A história de formação dos municípios integrantes do Parque é recente com exceção de Porto Murtinho que tem sua emancipação no século XIX, já os outros são da segunda metade do século $\mathrm{XX}^{11}$. Iremos abordar o histórico simplificado do município de Bodoquena pelo fato de o Assentamento Canaã fazer parte deste município.

O Município de Bodoquena apresenta o histórico de maior proximidade ao PNSB. Sua origem relaciona-se à criação de uma Colônia Agrícola no município de Miranda, no ano de $1948^{12}$. O núcleo dessa colônia foi estabelecido onde hoje é o Distrito de Morraria do Sul, quase ao lado da Terra Indígena Kadiwéu, mas naquela época a localidade ficou conhecida como Bodoquena (em alusão à serra). Até os anos 70, foi formada um faixa de plantações de café entre a Terra Indígena e o atual fragmento norte do parque. Além de mão-de-obra para a lavoura, a colônia atraiu indivíduos que passaram a ocupar terras dos índios (àquela época, ainda não demarcadas), resultando em tensão fundiária.

Na década de 1970, um confronto armado entre índios e colonos levou à evacuação do núcleo da colônia agrícola Bodoquena, cujos habitantes dirigiram-se para as proximidades do povoado mais próximo, chamado Vila Campão. A cafeicultura não prosperou devido às geadas, mas uma das principais fazendas produtoras, a Califórnia, apresentava parte de sua área no interior do parque. A área para onde os colonos se dirigiram, próxima à Vila Campão, veio a se constituir na sede do município de

10 ICMBio, Op. cit.

11 Para saber mais sobre o histórico dos municípios do Parque, ver ICMBio.

12 Decreto governamental no 547 de 30 de setembro de 1948. 
Bodoquena, emancipado de Miranda em $1980,{ }^{13}$ mas só no ano seguinte foi instalado institucionalmente o município. (ICMBio).

Ainda na década de 1980 começaram as ocupações da área onde se consolidaria o Assentamento Canaã, que de acordo com informações de moradores da área, existia interesse do proprietário da área em se "livrar" da fazenda de baixo valor de mercado, e alguns proprietários vizinhos tinham interesse na instalação da colônia, pois a mão-de-obra na região era escassa, outra hipótese das levantadas seria a exploração madeireira $^{14}$. Dessa forma, surge o Assentamento Canaã, em meio à polêmica que nortearia sua história até os dias atuais.

Observa-se a instalação do Canaã no local inadequado, pois a delimitação não respeitou regras básicas de produção muito menos a legislação ambiental, como a ocupação de encostas que em alguns pontos passa de $45^{\circ}$ de declividade ${ }^{15}$, vales e margens de rios. Nota-se o total desrespeito às legislações anteriores a criação do assentamento, bem como a condições de sobrevivência das pessoas inseridas nesse projeto de assentamento, a legislação, como o Código Florestal ${ }^{16}$. Deste texto vários pontos são ignorados na demarcação do Canaã como ainda a infraestrutura necessária ao funcionamento de uma comunidade rural.

Seguindo esta mesma linha de descaso social e ambiental, em 1986 foi criado no município de Bonito o assentamento Guaicurus, com 2.772 hectares de área. O assentamento está a Sudoeste da porção Norte do parque entre este a Terra Indígena Kadiwéu. Sobre o Guaicurus, Correa (2010) discute:

(...) a maioria dos moradores do Guaicurus continua roendo o osso duro da terra. O solo ali é tão rochoso que as plantas só despontam nas frinchas da pedra. Condenado à ociosidade pela falta de produção agrícola, o galpão do centro comunitário foi aproveitado como casa de festa. Depois que os assentados venderam para madeireiras as aroeiras, os vinháticos e os ipês da mata nativa, sobraram as paineiras, espetadas na paisagem meio lunar no assentamento, com o tronco esguio e as copas altas das árvores que cresceram no meio da floresta. Há lotes que o solo desertou de uma vez por todas,

13 Mato Grosso do Sul, (1980).

14 Estes dados foram coletados de conversas informais com os atores envolvidos no processo de criação do Parque e Assentamento, entendemos ser necessário citar os mesmos no trabalho, pois entendemos que estas informações fazem algum sentido quando analisamos a forma como muitas áreas são eleitas para projetos de reforma agrária em locais inadequados como no caso do Canaã.

15 Brasil, (1965).

${ }^{16}$ Lei $N^{\circ}$ 4.771, DE 15 DE SETEMBRO DE 1965. 
deixando para trás um lajeado estéril onde as casas de palha e telhado de plástico preto têm aparência provisória, muito parecida com a das cabanas que os sem-terra costumam armar nos acampamentos.

A Neotrópica tentou implantar no Guaicurus o mesmo projeto de ecodesenvolvimento ${ }^{17}$ que vingou no Santa Lúcia, um assentamento de 40 famílias numa antiga fazenda nos arredores de Bonito, encostada na cidade em terreno fértil. Mas ele não decolou no chão no Guaicurus, no Canaã e Sumatra, onde o cerrado lembra a paisagem áspera do agreste nordestino.

Além das deficiências de produção, nota-se a falta de infraestrutura relacionada ao abastecimento de água e energia em muitos casos, a falta de estradas como já foi citado anteriormente também se apresenta como um grave problema aos assentados.

A seguir apresenta-se uma tabela com informações referentes ao abastecimento de água, à existência de banheiro e destino do lixo nos três assentamentos do entorno do Parque, pois dependendo da forma como estes dados se apresentam pode-se ocorrer graves problemas de saúde.

${ }^{17}$ Fundação Neotrópica Brasil, 2002. 
Tabela 3 - Condições de saneamento e abastecimento de água nos assentamentos da zona de amortecimento do Parque.

\begin{tabular}{|c|c|c|c|c|c|c|c|c|c|}
\hline \multirow{2}{*}{\multicolumn{2}{|c|}{$\begin{array}{c}\text { Assentamento } \\
\mathrm{N}^{\mathbf{0}} \text { de domicílios }\end{array}$}} & \multirow{2}{*}{\multicolumn{2}{|c|}{$\begin{array}{c}\text { Canaã } \\
35\end{array}$}} & \multirow{2}{*}{\multicolumn{2}{|c|}{$\begin{array}{c}\text { Campinas } \\
29\end{array}$}} & \multirow{2}{*}{\multicolumn{2}{|c|}{$\begin{array}{c}\text { Santa Lucia } \\
12\end{array}$}} & \multirow{2}{*}{\multicolumn{2}{|c|}{$\begin{array}{c}\text { Guaicurus } \\
18\end{array}$}} \\
\hline & & & & & & & & & \\
\hline & & Qtd & $\%$ & Qtd & $\%$ & Qtd & $\%$ & Qtd & $\%$ \\
\hline \multirow{4}{*}{$\begin{array}{l}\text { Origem da } \\
\text { água } \\
\text { consumida }\end{array}$} & Rede geral & 1 & 2,9 & 2 & 6,9 & 6 & 50,0 & 7 & 38,9 \\
\hline & Poço ou nascente & 24 & 68,6 & 20 & 69,0 & 4 & 33,3 & 11 & 61,1 \\
\hline & Rio/Córrego & 10 & 28,6 & 4 & 13,8 & 1 & 8,3 & - & - \\
\hline & Outro & - & - & 3 & 10,3 & 1 & 8,3 & - & - \\
\hline \multirow{5}{*}{$\begin{array}{l}\text { Existência de } \\
\text { banheiro ou } \\
\text { sanitário }\end{array}$} & Fossa séptica & 20 & 57,1 & 20 & 69,0 & 7 & 58,3 & 13 & 72,2 \\
\hline & Fossa negra & 9 & 25,7 & 8 & 27,6 & 3 & 25,0 & 1 & 5,6 \\
\hline & Córrego/vala & 2 & 5,8 & - & - & - & - & 3 & 16,7 \\
\hline & Outro escoadouro & - & - & 1 & 3,4 & - & - & - & - \\
\hline & $\begin{array}{l}\text { não existe } \\
\text { privada }\end{array}$ & 4 & 11,4 & - & - & 2 & 16,7 & 1 & 5,6 \\
\hline \multirow{3}{*}{ Destino do lixo } & $\begin{array}{l}\text { Enterrado ou } \\
\text { jogado }\end{array}$ & 2 & 5,7 & 3 & 10,3 & - & - & 4 & 22,2 \\
\hline & Queimado & 31 & 88,6 & 25 & 86,2 & 12 & 100,0 & 14 & 77,8 \\
\hline & Outros & 2 & 5,7 & 1 & 3,4 & - & - & - & - \\
\hline
\end{tabular}

Fonte: ICMBio.

Org: RIBEIRO, A.F.N., 2010.

A implantação do PNSB nos municípios integrantes surgia na época, principalmente para Bodoquena, como uma tentativa de superação da estagnação que o município enfrenta desde a decadência econômica que o município enfrentava ${ }^{18}$.

De maneira geral, nos municípios inseridos no PNSB a principal atividade econômica é a criação de gado de corte ${ }^{19}$, plantação de soja e milho e de lavouras de subsistência, mineração de calcário, mármore, areia e cascalho, indústria de cimento ${ }^{20}$ no município de Bodoquena, turismo e pesca.

Nos assentamentos Campinas e Santa Lucia, com solos mais férteis, é comum o cultivo de pequenas plantações de frutas, mandioca, cana de açúcar, banana, etc. Uma das preocupações dos órgãos ambientais é que estas plantações geralmente se concentram próximas aos cursos d’água causando diversos tipos de danos à vegetação e ao próprio rio ${ }^{21}$. Existem inclusive casos de assentados do Canaã que usam terras de

18 Para aprofundamento neste tema, ver: Batarce, (2004).

19 Atualmente, as grandes lavouras mecanizadas (de soja e milho, principalmente) se concentram em regiões a leste e ao sul do Parque, assim como entre os seus dois fragmentos. Esta atividade teve seu apogeu na década de 1980 associada a fomentos e incentivos governamentais, mas no decorrer da década de 1990 com o fim dos incentivos a atividade deu lugar a pastagem para criação de gado.(ICMBIO)

20 É a maior indústria da região, Camargo Corrêa Industrial S/A - Cimento Cauê inaugurada em 1993.

\section{ICMBio.}




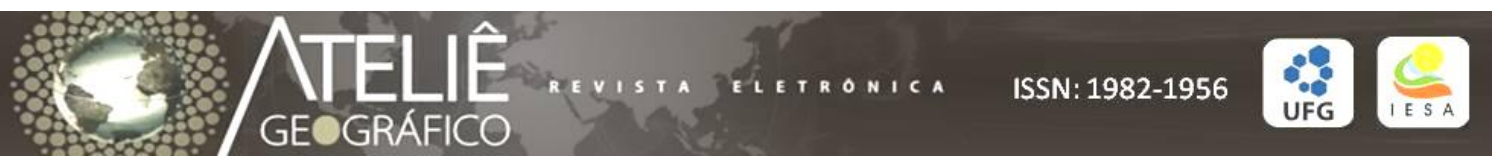

parentes ou arrendadas no Campinas ou em outras áreas no município como forma de colher algum produto para o consumo da família ou animais.

A produção da natureza pelos assentados com a implantação do Parque: teoria e prática, aproximação e distanciamento

A preocupação com as questões ambientais surge depois da Segunda Guerra Mundial, aliada a vários movimentos sociais de contestação aos problemas de vários segmentos. Sobretudo as preocupações surgem no momento que foi possível medir os índices de poluição no ar, na água e vários outros tipos de poluentes nocivos à saúde humana e do planeta.

Este episódio fez com que se multiplicassem os movimentos ambientalistas e as organizações em torno da defesa do meio ambiente e controle do avanço sobre as áreas ditas "naturais". Neste mesmo segmento, surge o chamado "desenvolvimento sustentável" que teoricamente busca um tipo de exploração controlada dos recursos naturais, sem comprometer as gerações futuras.

Sobre o surgimento do tema “desenvolvimento sustentável," Rodrigues, (1997) explica:

O termo (conceito?) Desenvolvimento Sustentável ganha amplitude após 1987 com a publicação do Relatório Nosso Futuro Comum que, em síntese, considera que é necessário continuar o desenvolvimento mas levando em conta a possibilidade de recomposição dos ecossistemas naturais. Acreditam, ou pelo menos parecem acreditar, que este processo poderá ser resolvido no modo industrial de produzir mais e mais mercadorias, ou seja, no mercado.

(...) Há ainda que se ponderar sobre a contradição dos dois termos: Desenvolvimento e Sustentabilidade. Desenvolver é uma meta a se atingir que compreende - no mundo moderno e pós moderno - na produção de mais e mais mercadorias. A produção contínua necessita tanto dos recursos naturais - que são extraídos de algum lugar - como de lugares que possam servir como depósitos para colocar os resíduos, destruindo ou pelo menos transformando a natureza de forma dupla, ou seja, pelo uso que os desgasta ou destrói e por utilizar lugares como depósito dos resíduos: água, ar e solo. (...)

Sustentabilidade significa manutenção das condições e que como já apontado não tem sido viável na produção de novas e continuas mercadorias. Há parasitas que, contraditoriamente, destroem sua própria base alimentar e é isto o que tem ocorrido com as formas pelas quais a sociedade capitalista, cuja proposta é a de produzir mais e sempre novas mercadorias, tidas como sinônimo de progresso e de desenvolvimento, tem ocasionado. Ou seja tem destruído sua base de recursos naturais. Há parasitas, contudo, que mantém pelo menos a possibilidade de continuar a se alimentar, permitindo a vida de sua base. Parece-me que este segundo tipo se aproxima do que tem sido abordado como desenvolvimento sustentável. (p. 89-90). 
Nessa discussão, podemos citar dois autores que fazem duras críticas ao modo de produção e às formas como a sociedade enfrenta esta contradição. A preocupação paira na ganância pelo chamado "desenvolvimento," sobretudo, no modelo adotado/construído após a Segunda Guerra Mundial. Nesse sentido, Castoriadis, (1987) nos alerta para o "preço" desse modelo de crescimento/progresso adotado.

\begin{abstract}
Com insistência crescente, começou-se a levantar a questão do "preço" que os seres humanos e as coletividades tinham de "pagar" pelo crescimento. Quase simultaneamente, "descobria-se" que esse preço envolvia um elemento importantíssimo, que até então tinha passado em silêncio, e cujas consequiências muitas vezes não diziam respeito diretamente às gerações presentes. Tratava-se do acúmulo maciço e talvez irreversível de danos infligidos à biosfera terrestre, resultante da interação destrutiva e cumulativa dos efeitos da industrialização; efeitos desencadeadores de reações ambientais que continuam, para além de um certo ponto, desconhecidas e imprevisíveis, e que poderiam eventualmente desembocar em uma avalanche catastrófica final, ultrapassando toda possibilidade de controle (...). (p. 137)
\end{abstract}

Já para Gonçalves (2004), este fato é discutido como "desafio ambiental”, ou seja, para o autor este fato é o centro das contradições da ideia de progresso e atualmente desenvolvimento:

\begin{abstract}
O desafio ambiental está no centro das contradições do mundo modernocolonial. Afinal, a idéia de progresso - e sua versão mais atual, desenvolvimento - é, rigorosamente, sinônimo de dominação da natureza! Portanto, aquilo que o ambientalismo apresentará como desafio é, exatamente, o que o projeto civilizatório, nas suas mais diferentes visões hegemônicas, acredita ser a solução: a idéia de dominação da natureza. $\mathrm{O}$ ambientalismo coloca-nos diante da questão de que há limites para dominação da natureza. Assim, além de um desafio técnico, estamos diante de um desafio político e, mesmo, civilizatório. (p. 24) (Grifos do autor)
\end{abstract}

As contradições expostas pelo autor, são observadas cotidianamente nas ruas, nos meios de comunicação e, sobretudo, arraigadas nas pessoas, no seu modo de vida. Estas acreditam que a superação dos problemas ambientais é a forma até hoje pautada nos sistemas de controle de emissão de gases, criação de unidades de conservação, economia de água ao banho e ao escovar os dentes, entre outras propagandas encabeçadas muitas vezes por pessoas famosas.

Acredita-se que as propostas de alternativas ao modelo de desenvolvimento podem ser prioritariamente agrupadas em dois eixos como nos aponta Moretti, (2007), preliminarmente identificados como principais, porém não são os únicos:

(...) um, de acordo com o dominante, tem o foco na correção de falhas no modelo de desenvolvimento, pressupõe a idéia de que o desenvolvimento 
técnico-científico apresentará soluções para os problemas sócio-ambientais, portanto, é uma questão de tempo a resolução dos problemas, têm como proposta concreta a internalização dos custos ambientais e na capacitação técnica dos trabalhadores para sua inserção na competitividade global, ou seja, não se constitui como uma alternativa, é a perpetuação do modelo de desenvolvimento utilizando outros indicadores; outro tem como base a idéia que os problemas sócio-ambientais estão inseridos na crise da modernidade capitalista e sua superação esta associada na construção de novas relações sociais, novos paradigmas, de novas práticas que superem a idéia da dicotomia sociedade/natureza, uma perspectiva para além do capital.

Para a ideia aqui apresentada identifica-se na segunda possibilidade a reflexão sobre o modo de produção baseado na pilhagem ambiental e exploração social.

No entendimento de Gonçalves, (2004), a superação do chamado desafio ambiental será possível através do uso de técnicas atuais, de acordo com ele:

A superação do desafio ambiental contemporâneo, com certeza, exigirá técnicas e, para isso, muitas das técnicas atuais serão assimiladas nesse processo, até que novas e outras sejam instituídas. Entretanto, sejam quais forem as técnicas, abrigarão em seu seio relações sociais e de poder.

Muitas vezes, a tentativa de superação, ou mesmo de conservação de alguns recursos ainda "preservados" em nossa fauna e flora é motivo de transformação destes ambientes em Unidades de Conservação e suas várias modalidades como segue a tabela.

Tabela 4 - Unidades de Conservação no Brasil

\begin{tabular}{|c|c|c|c|}
\hline Tipo de Unidade & Categoria & Qtd & Área* \\
\hline \multirow{5}{*}{ Proteção Integral - PI } & PI Esec - Estação Ecológica & 31 & $6.869 .411,18$ \\
\hline & MN - Monumento Natural & 2 & $44.179,73$ \\
\hline & Parna - Parque Nacional & 64 & $24.705 .236,36$ \\
\hline & Rebio - Reserva Biológica & 29 & $3.868 .939,47$ \\
\hline & Revis - Refúgio de Vida Silvestre & 5 & $169.103,88$ \\
\hline PI Total & & 131 & $35.656 .870,61$ \\
\hline \multirow{5}{*}{ Uso Sustentável - US } & US APA - Área de Proteção Ambiental & 31 & $9.899 .433,67$ \\
\hline & Arie - Área de Relevante Interesse Ecológico & 17 & $44.621,47$ \\
\hline & Flona - Floresta Nacional & 65 & $16.556 .903,48$ \\
\hline & RDS - Reserva de Desenvolvimento Sustentável & 1 & $64.441,29$ \\
\hline & Resex - Reserva Extrativista & 59 & $12.270 .116,44$ \\
\hline US Total & & 173 & $38.835 .516,35$ \\
\hline \multicolumn{2}{|l|}{ Total geral de Unidades } & 304 & $74.492 .386,96$ \\
\hline
\end{tabular}

A implantação e gerenciamento das Unidades de Conservação geram conflitos que perduram por vários anos, e com desfecho que na maioria das vezes desagrada parcela dos atores envolvidos, no caso deste trabalho analisa-se justamente a 
implantação de uma UC de Proteção Integral o PNSB e suas consequências sócio ambientais para as comunidades do entorno. De Acordo com Junior, Coutinho, Freitas, (2009).

Grande parte dos conflitos ocorre na escala local, pois é aí que se dão a materialização das relações socioespaciais eo exercício do poder, a partir dos fluxos de material e informação e das ações de coerção e de ordenamento territorial. (p. 57).

Corroborando com este tema Coelho, Cunha, Monteiro, (2009) reforçam esta ideia:

Se não são tão comuns hoje quanto no passado recente, os conflitos gerados pela criação de unidades de conservação à revelia das populações que dependem dos recursos naturais dessas áreas e se a criação de algumas unidades tem sido proposta enquanto estratégias de regularização fundiária e garantia de direitos das populações tradicionais, isso não quer dizer que a constituição de unidades de conservação deixou de ser marcada por contradições das mais diferentes ordens. (p. 68).

No caso analisado neste trabalho, a criação do PNSB incorporou parte do Assentamento Canaã em seu interior. Deixando de lado a questão da instalação deste assentamento em local inadequado, temos o caso de 34 lotes que ficaram impossibilitados de ser inseridos com os demais no processo produtivo, isto é, famílias que tiveram seu sustento comprometido pela sobreposição de uma UC de Proteção Integral. Como neste assentamento os colonos, que tinham sua situação cadastral regularizada, ${ }^{22}$ já contam com título definitivo da área, vários lotes já foram comercializados e as famílias da área de sobreposição foram buscando outras formas de sobrevivência fora do lote. De acordo com levantamentos informais no assentamento, na área de sobreposição restam aproximadamente 4 famílias $^{23}$ vivendo em condições extremas, pois não existem estradas e rede de energia nesta área.

Apesar da situação incerta que os assentados vivem até o momento, a criação do Parque é aceita pelos colonos, pois, de acordo com estudos de campo, não percebemos nenhuma rejeição aparente ao Parque, na totalidade. Tanto os inseridos na UC como os lotes do entorno se queixam da falta de solução para os lotes inseridos no

\footnotetext{
${ }^{22}$ Todos os financiamentos quitados e os impostos referentes ao lote pagos.

${ }^{23}$ Infelizmente não foi possível checar esses dados em campo pois as condições de estradas não permitiu a chegada a estas pessoas.
} 
Parque. Como podemos perceber nestas falas a seguir, quando foram questionados dos pontos positivos e negativos na criação do Parque segundo a visão dos assentados:

O positivo é que por ser um local de terras acidentadas precisa de preservação, a gente consegue perceber isso nos córregos, quando a gente chegou tinha locais que era possível se banhar, ai o pessoal foi desmatando, agora quando chove a terra desce toda para o rio e ai vai assoreando, então precisa preservar, criar uma reserva, porque tem muita planta que desapareceu, animais. Não se vê um bichinho nesse assentamento, o máximo que tem aqui é esse lobinho que pega galinha, mas você não vê uma anta, macaco, porque não tem habitat para ele, então acho que o parque veio para preservar algumas coisas que estão se perdendo e era uma área que já estava sendo explorada pelo homem de forma ilegal, foi uma forma de legalizar e impedir a exploração maior.

Os pontos negativos é que tem uma área do assentamento onde foi implantado o Parque, mas as pessoas estão dentro dele, e nenhuma administração que mobilize essa comunidade para parar de explorar o parque, no caso o pessoal que mora nos 34 lotes, eles não tem conhecimento de como utilizar a terra sem explorar o meio ambiente, eles continuam tirando madeira, desmatando. Criou-se uma área de preservação pegando lotes do assentamento, mas não foi feito nada pra tirar essas pessoas de lá. (Claudia Solange - Fevereiro de 2010)

Acho que tudo que vier em favor do Parque é bom, eu digo não pensando em mim, penso na nova geração, o que nos queremos é que favoreça os dois lados.

Os negativos é que eles criam as coisas e não regulamentam. (José Geraldo Fevereiro de 2010).

Diante dos fatos apresentados e das conversas informais com os assentados no decorrer da pesquisa, notamos uma profunda frustação tanto do projeto de reforma agrária do Estado como da criação da UC. O primeiro não acompanha os anseios de pessoas que buscam na terra seu sustento e de outro lado os que até o ano de 2000 resistiram na luta por se manterem no seu lote têm a noticia que seu lote "virou" um Parque.

Alguns assentados questionam se realmente é necessário que eles se retirem da área. Logicamente, o modelo de conservação Proteção Integral prevê este procedimento, mas entende-se que esta forma de preservar tem provocado muitos conflitos por conta de uma política de conservação defasada, em que simplesmente tem-se a visão que só é possível preservar a natureza separando o homem dela.

De acordo com Furlan (2000) apud Marinho, (2006):

Quando analisamos certos aspectos do modo como as sociedades se apropriam e transformam o mundo, pode parecer que é possível para o homem estar fora da natureza (...). Muitos chegam a propor que podemos nos afastar da natureza, como se ela não estivesse em nós mesmos. É como se a 
natureza pudesse existir num plano apenas ideal. Como se não fossemos natureza. (p. 21).

Seguindo mais além nesse tema, a autora nos fala da relação do tema com base nos estudos da geografia e enfatiza que

Este parece um dos nós mais difíceis de desatar quando discutimos Geografia. Ao humanizarmos demais o conceito de natureza, estamos antropomorfizando a natureza. Ao adotarmos uam postura animista, estamos naturalizando a sociedade. Porque caminhar pelos extremos? (Furlan, (2000) apud Marinho, (2006)).

De fato quando levamos a discussão para o lado da ciência, principalmente, da geografia, tem-se uma postura crítica, mas infelizmente não entende-se como uma crítica que vai além do discurso. Entende-se que a ciência deveria servir à sociedade de forma mais direta, mais impactante.

$\mathrm{Na}$ vida acadêmica, tem-se o contato com diversos autores que pesquisam, publicam e lutam por questões sociais, sejam elas de que natureza convier: habitação, saúde, reforma agrária, preservação, etc. Falta alguma ligação entre estes pesquisadores e a sociedade, pois as pesquisas deveriam chegar a quem realmente precisa, ou seja, o resultado de estudos deveriam resolver mais problemas sociais, como do Canaã, do Guaicurus e do PNSB como um todo, seus atores e coadjuvantes.

\section{Considerações Finais}

Historicamente a ocupação de Mato Grosso do Sul teve relação com a expansão da fronteira agrícola e abertura de novas áreas para agricultura, logicamente que o cenário se delineou para criação de gado, tanto que atualmente é o Estado com maior rebanho do Brasil em números de cabeças de gado, com aproximadamente 20.379.721 cabeças $^{24}$. Ainda a produção de soja, milho e cana de açúcar tem colocado o Estado em destaque no cenário nacional e internacional. Levando em consideração todas estas atividades citadas anteriormente, principalmente, a pecuária como a desenvolvida em Mato Grosso do Sul que requer grandes áreas para criação de animais, os problemas ambientais e sociais no campo tendem a se agravar.

A abertura de novas áreas para agricultura e pecuária tem devastado vários kilômetros quadrados de cerrado, e comprometido vários rios e nascentes com a poluição por agrotóxicos e o assoreamento de rios com a formação de bebedouros para 


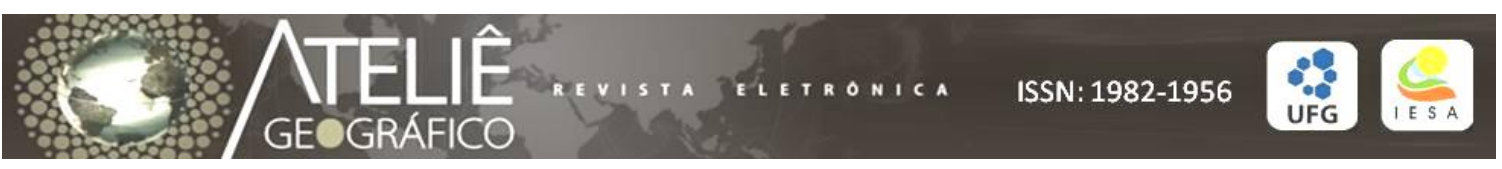

gado. Aliado aos problemas ambientais, temos a expropriação de várias famílias do campo por conta desse processo de abertura de novas áreas para agropecuária. Este problema tem causado o acúmulo de pessoas nas periferias das cidades e, sobretudo, aquelas que não conseguem sobrevivência na cidade voltam às margens de rodovias nos acampamentos de sem terra em busca de um novo pedaço de terra.

O histórico de formação das comunidades do entorno do PNSB se confunde com esse processo. De um lado, alguns assentamentos são criados para resolver um problema agrário de diversas pessoas que não têm um pedaço de terra para plantar, e de outro lado ocupa-se algumas áreas preservadas sem vocação agrícola para as condições econômica da maioria das pessoas inseridas nos projetos de reforma agrária e que posteriormente perceberiam que a área deveria ser terra de preservação, como é o caso do Assentamento Canaã.

O PNSB, implantado em setembro de 2000, tem em seu histórico de consolidação um profundo clima de conflito entre ONGs, políticos, fazendeiros e assentados. A criação do Parque coloca novamente a discussão do modelo de conservação pautada em Parques, ${ }^{25}$ pois a delimitação da UC sobrepôs 34 lotes do assentamento Canaã em seus domínios, para agravar ainda mais a situação destes colonos.

Entende-se que a criação do PNSB é de fundamental importância para região, principalmente por se tratar de uma das únicas reservas de cerrado ainda preservado, e a grande capacidade de nascentes que o local abriga, sem falar na fauna cavernícola que é muito rica. Mas esse impasse existente entre os assentados e o Parque que não pode ser mais prolongado, haja vista que a incerteza paira inclusive para as pessoas na Zona de Amortecimento.

Tem-se a ideia de que os problemas sociais e ambientais são questões distintas e devem ser pensadas separadamente. A mesma concepção que a sociedade ocidental tem a respeito da relação homem natureza, ou seja, não pode fragmentar algo único, que vive em função do outro. O mundo é formado por ciclos, tudo é interdependente, se a menor parte sofrer alteração o todo será modificado. Diante dessa concepção, entendese a relação homem natureza e os problemas socioambientais, pois a partir do momento

\footnotetext{
${ }^{24}$ IBGE, Censo Agropecuário. 2006.

${ }^{25}$ Unidades de Conservação de Proteção Integral. (SNUC, 2000).
} 


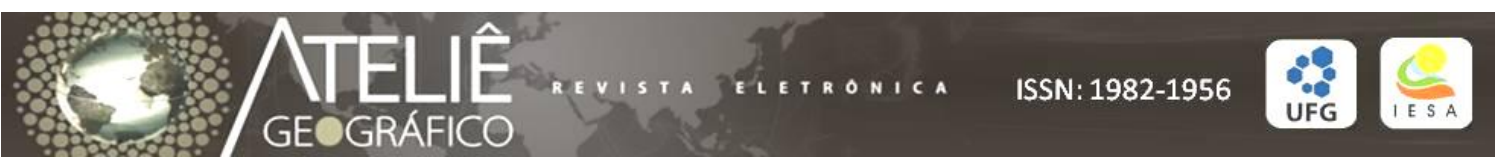

que estes forem vistos e entendidos como algo único e interdependente provavelmente serão criados mecanismos para solução.

\section{Referências Bibliográficas}

BATARCE, A. P. A. Unidades de Conservação e Produção do Espaço. O Parque Nacional da Serra da Bodoquena. Dourados-MS: UFMS, CPDO, 2004. (Dissertação de Mestrado).

BOGGIANI, P.C. Serra da Bodoquena: Parque Nacional ou APA?. Disponível em: http://www.unb.br/ig/pvista/ParqueSerraBodoquena.htm - Acesso em 24/09/2007.

BRASIL. Lei No 4.771, DE 15 DE SETEMBRO DE 1965. Institui o Código Florestal.

BRASIL. Lei $\mathrm{n}^{\circ} 9.985$ de 18 de julho de 2000. Diário Oficial. Institui o Sistema Nacional de Unidades de Conservação da Natureza - SNUC. 2000.

BRASIL. Resolução CONAMA Nº 13/90, DE 6 DE DEZEMBRO DE 1990.

CASTORIADIS, C. As encruzilhadas do labirinto 2. Os domínios do homem. Rio de Janeiro: Paz e Terra, 1987.

COELHO, M.C.N. et al. Unidades de Conservação: Populações, recursos e territórios. Abordagens da geografia. In: GUERRA, A.J.T; COELHO, M.C.N (Orgs.). Unidade de conservação: abordagens e características geográficas. Rio de Janeiro: Bertrand Brasil, 2009.

CORREA, M.S. De sem-terra a com-pedra. Disponível em http://www.oeco.com.br/marcos-sa-correa?start=175 - Acesso em 15/06/10.

Fundação Neotrópica Brasil. PLANO DE ECODESENVOLVIMENTO DO ENTORNO DO PARQUE NACIONAL DA SERRA DA BODOQUENA. Campo Grande, setembro de 2002.

GONÇALVES, C.W.P. O desafio ambiental. Rio de Janeiro: Record, 2004. Organizado por Emir Sader.

IBGE. Censo 2000. Disponível em: www.ibge.gov.br - Acesso em 20/05/2010.

IBGE. Censo Agropecuário 2006. Disponível em: www.ibge.gov.br - Acesso em 20/05/2010.

ICMBIO. Encartes do Plano de Manejo do Parque Nacional da Serra da Bodoquena. (Em elaboração)

Instituto Chico Mendes de Conservação da Biodiversidade - ICMBio. UNIDADES DE 
CONSERVAÇÃO FEDERAIS, CENTROS ESPECIALIZADOS E COORDENAÇÕES REGIONAIS, 2009. Disponível em: www.icmbio.gov.br Acesso em 20/06/2010.

JÚNIOR, E.C et al. Gestão da Biodiversidade e áreas protegidas. In: GUERRA, A.J.T; COELHO, M.C.N (Orgs.). Unidade de conservação: abordagens e características geográficas. Rio de Janeiro: Bertrand Brasil, 2009.

MARINHO, M.A. Conflitos e Possíveis diálogos entre Unidades de Conservação e Populações Camponesas: Uma análise do Parque Estadual Intervales e o Bairro do Guapiruvu (Vale do Ribeira/SP). Universidade de São Paulo, São Paulo, 2006. (dissertação de Mestrado)

Mato Grosso do Sul. Decreto governamental nº 547 de 30 de setembro de 1948.

Mato Grosso do Sul. Lei Estadual nº 87 de 13 de maio de 1980.

MOREIRA, R. Prefácio. In: SANTOS, D. A reinvenção do Espaço: diálogos em torno da construção do significado de uma categoria. São Paulo: Editora da UNESP, 2002.

MORETTI, E. C. Relatório de Pós-Doutoramento, UNICAMP: 2007. (apostilado).

RODRIGUES, A. M. Desenvolvimento sustentável e atividade turística. In: LUCHIARI, M. T. D. P.(org). Turismo e Meio Ambiente. Campinas: IFCH Unicamp, Coleção Textos Didáticos, Vol. 2, nº 31(2), 1997.

Recebido para publicação em março de 2011

Aprovado para publicação em abril de 2011 